\title{
A Defense of Experiential Realism: The Need to Take Phenomenological Reality on Its Own Terms in the Study of the Mind
}

\author{
Stan B. Klein \\ University of California, Santa Barbara
}

\begin{abstract}
In this article I argue for the importance of treating mental experience on its own terms. In defense of "experiential realism," I offer a critique of modern psychology's all-toofrequent attempts to effect an objectification and quantification of personal subjectivity. The question is "What can we learn about experiential reality from indices that, in the service of scientific objectification, transform the qualitative properties of experience into quantitative proxies?" I conclude that such treatment is neither necessary for realizing, nor sufficient for capturing, subjectively given states (such as perception, pain, imagery, fear, thought, memory) — that is, for understanding many of the principle objects of psychological inquiry. A "science of mind" that approaches its subject matter from a third-person perspective should, I contend, be treated with a healthy amount of informed skepticism.
\end{abstract}

Keywords: consciousness, experiential states, scientific materialism

\begin{abstract}
Some years ago I was questioned by a visiting Tibetan monk about how psychology was studied in the West. Carefully I tried to delineate our fields of psychologycognition with its subareas such as attention and memory, personality psychology, developmental, and so on. He looked puzzled. I attempted to explain what we meant by empirical method. He seemed even more puzzled. I talked about operational definitions and described some psychological experiments. Suddenly his look of intensely interested bewilderment turned to one of insight: "Aha! So you are saying that in America people teach and write about psychology [the mind] who have no meditation practice?" "Yes, of course," I answered. "But then how can they know anything!" and then, giving me a piercing look, he asked, "Do you think that's ethical?" (Rosch, 1997, p. 185)
\end{abstract}

Imagine a very simple experiment in which there are present three persons: an experimenter and two participants (henceforth $\mathrm{E}, \mathrm{P}_{1}$, and $\mathrm{P}_{2}$ ). E tells $\mathrm{P}_{1}$ and $\mathrm{P}_{2}$ : "A list of 20 animal names

This article was published Online First February 2, 2015. I thank Galen Strawson for suggesting the quote at the beginning of this article, as well as for insightful comments on the text. I also appreciate two anonymous reviewers for their helpful suggestions and Steve Lynn for his support with this project.

Correspondence concerning this article should be addressed to Stan B. Klein, Department of Psychological and Brain Sciences, 551 Ucen Road, University of California at Santa Barbara, Santa Barbara, CA 93106. E-mail: klein@ psych.ucsb.edu (e.g., dog, bird) will appear, one at a time, on the screen before you. Once the words have been shown, there will be a brief delay, after which you will be asked to remember, in any order, as many of the names as you can." The experiment commences. On completion, the results reveal that $\mathrm{P}_{1}$ and $\mathrm{P}_{2}$ both remember 7 of the 20 presented names.

This minimalist scenario captures the essentials of many experimental treatments of memory: Stimulus information is presented, and participants (assigned to conditions dictated by the hypothesis of interest) are requested to remember (e.g., recall, recognize) the previously presented information during some predetermined interval. ${ }^{1}$ Although various methods can be used to analyze a participant's performance (e.g., numeric, temporal, qualitative), most entail assignment of a number to each persons' memory report (e.g., number of items recognized, recall latency, number of items exempli-

\footnotetext{
${ }^{1}$ To maintain focus on participants' memorial experiences, I intentionally have left unspecified the purpose of the study, experimental manipulations, properties of the stimulus items, and so on. If the reader finds this minimalist approach troubling, feel free to fill in details with your favorite memory study (e.g., depth of processing; the selfgeneration effect). The points I am trying to make should not be seriously compromised by specifics.
} 
fying property $\mathrm{X}$; where the rules by which numerals are assigned are assumed to reflect properties of a particular scale of measurement; e.g., Stevens, 1946). Those numbers then are statistically analyzed and, in conjunction with the hypothesis under scrutiny, used to generate inferences about the memorial experiences for which they stand proxy.

So, what can our hypothetical experimenter infer about her hypothetical participants' memory? Well, she certainly is entitled to draw conclusions concerning the number of responses $\mathrm{P}_{1}$ and $\mathrm{P}_{2}$ produced: Their memorial performance can be described as consisting in a "numerical identity." But beyond this somewhat trivial fact, what else do our data permit her to say about participants' memories?

The answer is "not much." ${ }^{2}$ Having reduced $\mathrm{P}_{1}$ and $\mathrm{P}_{2}$ 's memories to numeric values, these become E's sole point of entry into participants' memorial experience. And that point of entry leads to an epistemic dead end: By transposing memory experience into quantitative formalism (in this case via the act of counting), she has stripped experience of all but its numeric properties (e.g., means, measures of variability). And such quantitative evidence sheds, at best, a dim light on the nonnumeric properties of memory experience.

At first blush, this may strike the reader as a bit odd. After all, quantitative equivalence, strictly speaking, assumes property equivalence: That is, $\mathrm{X}$ and $\mathrm{Y}$ are numerically identical if and only if every property true of $\mathrm{X}$ is true of $Y$ as well (i.e., Leibniz's "indiscernibility of identicals"; e.g., Williams, 2002). But, numeric identity was obtained by reducing the richness of $\mathrm{P}_{1}$ and $\mathrm{P}_{2}$ 's memorial experience to values on a scale of measurement (presumably in the service of scientific objectification), thus removing from consideration all properties other than those that can be represented by number. And this leaves little room for informed inferences about the experiential bases of the numeric equivalence.

So, to the question: "What does the demonstration of quantitative equivalence sanction with respect to inferences about memory?" the answer is that "recall performance for $\mathrm{P}_{1}$ and $\mathrm{P}_{2}$ was numerically identical with respect to the property "number recalled." But this simply describes a quantitative aspect of reality (which may be of interest to a particular hypothesis) — it does not tell us in what way or ways nonnumeric properties of memory experience were the same (or if indeed they were). It thus leaves little for further inference.

For instance, did $\mathrm{P}_{1}$ and $\mathrm{P}_{2}$ recall the same 7 animal names? Let's assume they did. Did they report those items in the same order? Again, suppose that to be the case. In what manner were those reports realized in experience: as propositions, images, some combination, something else? Assume both participants formed images of the animals whose names they remembered. Were those images in color or black-and-white? Were the images formed by $\mathrm{P}_{1}$ more or less clear, more or less detailed, more or less complete than those of $\mathrm{P}_{2}$ ?

Suppose $\mathrm{P}_{1}$ and $\mathrm{P}_{2}$ both recall (accurately) the word "bird." Was the image on which their report was based a robin, sparrow, canary, eagle, penguin? Was it accompanied by associations (personal or nonpersonal; social or a-social) or feelings (positive or negative)? If so, were these accompanying states intrinsic to the reported content (e.g., not just any bird, but my beloved bird Sammy) or just knowable addenda (e.g., birds are related to dinosaurs)? Did these accompaniments enhance or impede (or have no effect on) the actualization of the image in awareness? In short, in what exactly did the conscious grasp of "bird" consist in? All we can say with assurance is that memory experience occurred, and that this occurrence served as the evidential basis for assigning it a numeric label.

\section{The Science of Psychology}

These considerations highlight a basic problem with the psychological treatment of experiential states: How can an investigator wishing to understand a person's mental state (e.g., memory, imagery, thought, inference, desire, judgment, fear) provide an adequate causal account from behavioral reports if those reports make no reference to such states? To conflate (or just ignore the difference between) two

\footnotetext{
${ }^{2}$ Some might feel we are entitled to say more because the hypothesis under consideration provides the conceptual grounding for the numeric identity. But, this assumes that participants' numeric equivalence can be treated as synonymous - when conjoined with hypothesis-with experiential (or sub-experiential) properties. And this has not beenand, as I will argue in this article, cannot be-demonstrated.
} 
clearly distinguishable ways of treating experience (i.e., in terms of their quantitative or qualitative properties) is conceptually counterproductive (Note: My focus is on the empirical treatment of things that manifest as mental experience, not the nature of experience itself).

Well, what benefit(s) do psychologists derive from the reduction of mental phenomena to numeric data? The most probable answer is that reduction provides psychological investigation with an air of scientific respectability. And psychology, for much of its existence as an independent academic pursuit, has worked hard to achieve such credibility (a goal expressed with admirable candor by foundational experimentalists; e.g., Ebbinghaus, 1885/1913). But, as I hope to show, quantitative data are not of equal epistemic value for all aspects of reality. Specifically, while material aspects of reality may be profitably interrogated via numeric reduction, application of this technique to the experiential aspects comes at a considerable cost.

\section{The Metaphysical Assumptions of Contemporary Science and Its Influence on Psychological Research}

Methodological and conceptual reduction is characteristic of most modern science (e.g., Klee, 1997; Margenau, 1950; Medawar, 1968/ 1980; Trusted, 1999). The basic idea is that complex phenomena should be analyzed into their constituents, with the goal of arriving at laws predicting how these parts function collectively at different levels of complexity. This reductive strategy typically is conjoined with two metaphysical postulates: (a) that nature is a reflection of the underlying mathematical order of reality, and (b) that reality, in its entirety, is composed of material substances.

According to the first postulate, nature's intelligibility is subsumable, in its entirety, under mathematically formulable laws. This ideathat only by mathematical induction can the truths of nature be known- has roots in Greek antiquity (i.e., the Pythagoreans; e.g., Koestler, 1959). The second postulate-that reality is entirely physical-is of more recent vintage, gaining traction during the ascendency of physics as the sine qua non of science in the 17th century (e.g., Reichenbach, 1951). It widely has been taken (though not necessarily on logical or empirically sanctioned grounds) as an endorsement of the stipulation that facts about reality expressed outside the vocabulary of (an ideally true) physics can be re-expressed wholly within that vocabulary. Both postulates are nicely captured by Galileo's well-known dictum that anything not involving the study of the quantifiable properties of material bodies does not deserve to be called science.

Psychology, struggling to free itself of the shackles of natural philosophy (to which it still was tethered in the early part of the 19th century) took pains to position itself as a scientific approach to the study of mind. The obvious path to scientific respectability was to model one's methodological commitments on the principles embodied by the sciences, in particular physics ("All science aspires to be like physics"; Wolpert, 1992, p. 121). Accordingly, the goal of objectivity gradually assumed a place of methodological and conceptual prominence (save for more clinically oriented endeavors) in psychological inquiry (e.g., Danziger, 2008). In contrast, subjectivity, increasingly seen as lacking the requisite qualities for a scientific approach to mind (e.g., Dewey, 1958; Kohler, 1938; Robinson, 2008), either was placed off-limits or viewed as little more than a curious epiphenomenon whose realization could be subsumed entirely in terms of subexperiential, materially based (primarily neural) processes. In this way, subjectivity gradually was banished from the study of mind (e.g., Gallagher \& Zahavi, 2008; Klein, 2014; Nagel, 2012; Varela, Thompson, \& Rosch, 1993).

\section{A Consequence of Banning Subjectivity From the Investigation of Psychological Phenomena}

According subjectivity, at best, "second class citizenship" in the study of mind is particularly ironic in virtue of the fact that subjectivity is the very thing that makes the scientific pursuit of such knowledge (actually any knowledge) possible. Timing devices, neuroimaging technologies, electroencephalographs, and a host of modern means of obtaining objective knowledge about mind are useless absent an experiencing subject. As Gallagher and Zahavi (2008) point out, "Science is performed by somebody; it is a specific theoretical stance toward the world ... scientific objectivity is something we strive for but it rests on the observations of 
individuals" (p. 41). To believe otherwise has the absurd consequence of rendering our knowledge of mind (or, more generally, reality) dependent, in its entirety, on the provisions of an experiential conduit stipulated either to be unworthy of study or essentially nonexistent (Klein, 2014). As Strawson (2009) notes, "We know nothing about (nature) when we consider it independently of the occurrent mental goings-on of which it is supposed to be the ground" (p. 119; parenthesis added for clarity of exposition). (Refer to Table 1 for explication of several of the key terms I use in this paper).

This untoward treatment of subjectivity resulted largely from a scientific precommitment (i.e., a presumption that plays a critical - though often unquestioned-role in shaping the formative background of the questions we address to nature; e.g., Rescher, 1984) consisting in the conjunction of materialist dogma (i.e., all reality is physical) with deep veneration for the principle that "all is number." Robinson (2008) nicely summarizes the metaphysical commitments of modern science: "Physics, if it is ever 'complete,' completely accounts for and predicts the sorts of physical events and properties for which physicalist modes of inquiry and measurement are authoritative" (p. 23).
But are these prescientific commitments (which often are counted as part of science) necessarily "authoritative" in the domain of experiential reality? In a word, "no." Inductions and prognostications always should be called into question when their applicability is extended to cases significantly different from those to which the evidence pertains. Putting it another, perhaps better, way, the inferential warrant of any method or set of methods reaches only so far as those aspects of reality for which it has been fitted. And, because we currently have no way of surveying the whole of reality (e.g., Eddington, 1958; Elvee, 1992; Klein, 2014; Margenau, 1950; Martin, 2008), it would seem wise not to "close our ignorance through impatience with the infinity of the absolute itself" (Earle, 1955, p. 89). As Meixner (2008) sees it: "Materialism is regarded as being identical with, or implied, by, the scientific worldview. But it is never inquired whether there even is such a thing as the scientific worldview . . . indeed, are there not more worldviews than one that are not only compatible with, but actually good for science? Perhaps there even is a worldview that is better for science than the materialistic one?" (p. 157; emphasis in original).

Table 1

Notes on Some Key Terms

Table 1 spells out the intended meaning of several terms that play an important role in this article. Its reason for inclusion is twofold. First, explicit specification of my (perhaps idiosyncratic) conceptualization of these central terms seems warranted. Second, some of these terms have more than one colloquially accepted use (e.g., experience); accordingly, a precise treatment of their present usage helps establish a common referential base. While not everyone will agree with my definitions, there should be little question of the meanings I intend.

1. Mental state: X is a mental state only if and only if it there is "something it is like" (e.g., Nagel, 1974) for the organism to have that state. A mental state contains both contentful (e.g., objects of awareness-what is sometimes called its intentional object; e.g., Brentano, 1995), as well as qualitative (i.e., the subjective feel of that content) aspects (Note: Someone who considers mental states to include dispositions would not accept this definition, since on most views a disposition can exist absent its conscious realization-e.g., having a belief during dreamless sleep. My reasons for counting belief as a nondispositional mental state are given in Klein, in press).

This is not to imply that mental states cannot be underwritten by nonexperiential constituents. Current wisdom is that a mental state is the experiential outcome of a process (or set of processes) that have subexperiential aspects supporting its realization. While these subexperiential preconditions are necessary for realizing the mental state, they are nonmental in the sense that they are mechanisms that help make experience possible, but are not the experience itself - that is, as felt. They conceivably could go on without there being any experience. An analogy suggested by Galen Strawson may help: A play consists in a great deal of behind the scenes activity, but, strictly speaking, none of this activity is the play per se. All mental states are experiential.

2. Experience: Experience is the qualitative aspect of the mental states you are having right now-i.e., how they feel to the experiencer. This is what most philosophers have in mind when they talk about consciousness. In my usage, all experience is conscious experience. While some who use the term "experience" have in mind sensation (e.g., pain) and perception (e.g., that tree over there), experience, as I use the term, can take as its intentional object such things as thought, belief, memory and other mental content. In this way, experience can be cognitive as well as sensorial. 
In short, the presumed authoritative status of the scientific approach to reality does not derive from discovered facts or logical principles, but rather from subjectively informed presuppositions, sanctioned in large measure by the pragmatic serviceability of the (physical) products they make possible. Maintaining that all of reality can be captured by the concepts, methods, and instruments of a particular approach (e.g., physics) is a metaphysical conceit lying outside what can be operationally defended or conceptually justified (e.g., Eddington, 1958; Kitchener, 1988; Klein, 2014; Margenau, 1984; Martin, 2008; Meixner, 2008; Nagel, 2012; Robinson, 2010; Swinburne, 2013; Tallis, 2008; Trusted, 1999; Vaihinger, 1925).

\section{Goals of the Present Article}

I do not reject science as an approach to reality. It has proven to be an immeasurably successful way to question nature and has greatly enhanced our understanding of those aspects of reality in which it is "authoritative"- that is, those aspects (the physical) it was designed to address. What I am arguing is that, contrary to much current opinion, it is far from clear that science (at least as presently configured) is the sole (or appropriate) avenue to all truths about all of reality.

My goal is not to examine all of the philosophical positions (and their variants [and their variants]) crafted to enhance or diminish the epistemic warrant of scientific metaphysics-for example, materialism (neutral, radical, redescriptive, nonreductive, emergent [epistemological, ontological]), constructivism, eliminativism, panpsychism, parallelism, idealism (solipsistic, absolute), phenomenalism, dualism (property, substance [Cartesian and non-Cartesian]), and so forth. Treatment of these largely disjunctive views of reality would take me far afield, and I seriously doubt-given the number of (mostly incompatible) philosophical formalizations proposed - that any satisfactory resolution could reasonably be expected.

My goal is more modest. I wish to take issue with the (typically implicit) assumption that our current scientific methods have exhausted our ways of apprehending and knowing reality. "Render to science what belongs to science, but we should not surrender all of reality too hastily lest we fail to encounter vast mysteries not accommodated by its particular set of assumptions and methodologies" (Klein, 2012, p. 508).
The "mystery" I have in mind is that of the mental aspects of reality (as exemplified by our experiential states). As most materialists will concede-if forced to offer an opinionexperiential phenomena are among the most difficult aspects of reality for their view to handle (e.g., BonJour, 2010; Meixner, 2008; Nagel, 2012; Robinson, 2008; Strawson, 2009). The question I pose is "what can we learn about experiential reality from behavioral indices that, in the service of scientific objectification, transform the qualitative properties of experience into quantitative measures?"

\section{Saving the Phenomena}

In light of considerations voiced in the section titled The Science of Psychology, a "science of mind" that approaches its subject matter from a third-person perspective should be treated with a healthy dose of skepticism. Objectification is neither necessary for realizing, nor sufficient for capturing, subjectively given states such as perception, pain, imagery, fear, thought, memory - that is, for understanding mental experience on its own terms. Nor do there currently exist bridging laws that enable one to move from the physical to the experiential aspects of reality without reducing the latter out of existence (e.g., Chalmers, 1996; Klee, 1997; Klein, 2014; Strawson, 2009). In short, by adopting the idealized formalizations of mathematical physics as our model for the study of human experience, we run a serious risk of failing to capture the depth and complexity of the object of reduction-our phenomenology (e.g., Klein, 2014; Koestler \& Smythies, 1967; Kohler, 1938; Varela et al., 1993; Wallace, 2003).

In this article, I often will conflate objectification and quantification. While they go handin-hand in much of modern science, they are neither conceptual nor methodological equivalents. However, given the metaphysical commitments of science enumerated in The Science of Psychology, the case can be made that most instances of scientific objectification presume-or entail-quantification.

\section{The Experiential Reality of Mental States}

Thus far, I have drawn a conceptual distinction between first- and third-person-generated ontologies. However, a conceptual distinction, 
no matter how well crafted, does not license the conclusion that the distinction holds at the level of personal experience-nor does the fact that scientists have an abstract category for a mental entity guarantee that an ontological correlate exists. A conceptualization drawn in an entirely theoretical way is a discourse about, not a rendering of, experience (e.g., Varela et al., 1993). What we need is a way to connect theoretical arguments for, to the subjective aspects of, reality as they are given in experience.

In this section, I offer a phenomenological defense of experiential realism. To do so, I examine the introspective experiences of an individual (let's call her Emily). While the presented scenario-adapted from BonJour (2010) - is fictional, I trust the reader will find nothing extraordinary in its rendition: In almost every way, the story is, for lack of a better word, patently mundane.

Imagine Emily lying motionless in a fragrant meadow on a sunny day. Despite her lack of (overt) behavior, a great deal is happening. Emily sees the sun shining brightly, smells the aroma of wild flowers, hears the buzzing of bees, and feels the grass pressing gently on her back. More, she remembers a situation from her youth in which she reclined in her backyard watching the clouds pass overhead, thinks about work to be done once she leaves this idyllic setting, and makes plans to accomplish her obligations. In short, all this (and likely much more) is going on in her mind as she lays motionless.

This story-a glimpse into what might be going on in Emily's mind (i.e., her mental experiences) - does not entail any behavior observable from a third-person perspective. Indeed, there is no objective behavior to describe. All that transpires is first-person subjectivitythat is, a collection of mental states (the terms underlined in the previous paragraph), many of which do not have any direct behavioral correlates (e.g., feeling the touch of the soft grass on one's skin). While one can stipulate that internal behavior (e.g., brain activity) must underwrite Emily's experiential states, there currently are no laws capable of explaining how this is accomplished (e.g., how the behavior of neurons results in subjective experience). And, despite the claims of "promissory note materialism" (e.g., Churchland, 1986), none seem in the offing.

There thus is an aspect of Emily's reality (her experience) whose physicality is, at best, deriv- ative-for example, Emily could, should she choose, give voice to her experiences. But that is her conscious decision to transform her phenomenological reality into socially consensual convention. ${ }^{3}$ And, in the process, much will be lost: We have great difficulty finding words to capture the richness of sensory experience. Redescribing the experiential elements of Emily's subjective reality in the vocabulary of physics (or physiology, or contemporary psychology) is likely to truncate (or eliminate) the phenomena under description.

\section{Experiential and Physical Aspects of Reality}

Reality, in its most general sense, is taken to mean everything that has being; that is, everything that exists. Although this concept has been subject to considerable discussion and emendation over the centuries, Western science presently holds there is only one reality - one totality of beingand that "reality" is physical to its core.

But, as I hope both the conceptual and phenomenological arguments presented have shown, there are reasons to doubt whether certain aspects of reality can be fitted to the physical without suffering serious loss of content and meaning. These include such things as sights, sounds, thoughts, love, hate, jealousy, images, inferences, memories, ambition, suffering, happiness, beauty, ugliness, dreams, hopes, feelings, beliefs, doubts, wisdom, stupidity, the pull of the past, the anticipation of the future - that is, the mental states that capture the attention and empirical interests of psychological investigation.

The relation between physical and mental (i.e., experiential) reality, as Tulving and Szpunar (2012) see it, is complicated. "Although mental reality is utterly dependent on physical reality, in the sense that it could not exist in the absence of physical reality, it also is independent of physical reality in the sense that what exists in mental reality does not exist in physical reality ... There are no thoughts, images, mem-

\footnotetext{
${ }^{3}$ Emily may, of course, decide to say nothing of her phenomenology because she wants to eliminate experiencedescribing terminology from her account of reality (perhaps she is eliminative materialist). But, if so, she is choosing to leave part of reality out of her account. For if one thing is clear, it is that "experience is as real as rabbits and rocks. Indeed, its reality is still, in this post-post-Cartesian age, the thing we can be most certain of" (Strawson, 2009, p. 103).
} 
ories . . experiences, dreams, feelings, hopes, fears . . . in physical reality" (p. 258). They continue, "The converse also is true, there is not a single thing that exists in physical reality that also exists in mental reality. There are no rivers or mountains, trees or flowers, no brain, no blood, no neurons or synapses, no molecules of atoms in mental reality" (p. 258).

While this may sound like Cartesian substance dualism (e.g., Descartes, 1984), the authors take serious objection to such categorization. "Like all other cognitive neuroscientists we accept as axiomatic that mental reality is fully dependent on the brain, is continuous with the brain and the rest of physical reality. The brain and the mind are made of the 'same stuff.' We do not yet know what that 'stuff' is but we have reason to believe that eventually it will be discovered. Contrary to what some people like to declare, we know that the brain and mind are not identical. The brain and the mind are different entities constituted of the same basic 'stuff"' (Tulving \& Szpunar, 2012, p. 258). (This position could still be characterized as a form of dualism, albeit a dualism of property rather than substance).

I do not endorse the metaphysical assumption that mind and brain necessarily reduce to the same "stuff" (although this view could be accommodated, e.g., by a version of emergent materialism). However, I fully agree with Tulving and Szpunar's main conclusion: Phenomena occurring at the level of the mental, though dependent in "some way" on properties of the physical, are neither reducible to, nor fully explicable in terms of, purely materialist considerations (see also Jackson, 1986; Klein, 2014; Martin, 2008; Meixner, 2005; Strawson, 2009).

We must, of both practical and theoretical necessity, accord mental reality its place in our inventory of "what is." To this end, we would be well advised to deal with experiential offerings at the level at which they manifest in awareness. Fodor (1974) expresses this sentiment with characteristic directness, asserting that it is not required "that the taxonomies which the special sciences (e.g., psychology) employ must themselves reduce to the taxonomy of physics. It is not required, and it is probably not true" (p. 114; parenthesis added for clarification).

\section{Taking Stock: A Brief Summing Up}

Thus far, I have tried to make the case for remaining open to the possibility that "reality" in its fullness is constituted by a plurality of aspects that likely share different ontological commitments (for a different perspective on the ontological relation between the physical and mental, see Russell, 1921/1949; Strawson, 2009). The alternative, favored by contemporary science, is to force reality - that is, "all there is"-into a presently unverifiable materialistic metaphysic. If psychologists adopt this approach, we run a serious risk of stripping away those aspects of the "whole" that make an experience the experience that it is. By contrast, if we embrace the former perspective, we remain receptive to reality in the richness with which it is given.

The aspect of reality of relevance to the issues under discussion is first-person experience. This is not something that satisfactorily can be captured via third-party descriptive acts or a purely theoretical rendering; our phenomenology can be fully appreciated only via direct, nonanalytic acquaintance with its experiential offerings (for related views, see Jackson, 1986; Klein, 2014; Kohler, 1938; Robinson, 2010; Strawson, 2009). This acquaintance provides the palate that gives color, form, and texture to our mental landscape (e.g., Jackson, 1986; James, 1907/1975; Strawson, 2009). ${ }^{4}$

In short, the psychological topography of our phenomenology is given by first-person acquaintance with the experiential states in which they are realized (e.g., Gallagher \& Zahavi, 2008; Klein, 2014; Midgley, 2014; Nagel, 2012). There is simply no other way to reliably know what a mental state, qua mental state, entails (Kohler, 1938; Varela et al., 1993). While experience eventually may prove grounded in events taking place at the neural, molecular, atomic, or subatomic level, reducing our phenomenology to the motion, shape, and size of these constituents (or knowledge thereof) cannot provide the information we ac-

\footnotetext{
${ }^{4}$ This is not to say we have first-person access to all the workings of our minds. In many (perhaps most) cases we do not (e.g., Nisbett \& Wilson, 1977). But we do have a privileged relation with the experienced outcomes of the workings of our neural machinery (e.g., Gallagher, 2000; Klein, in press; Robinson, 2008; Strawson, 2009).
} 
quire in virtue of having the experience. As Varela et al. (1993) note: "When it is cognition or mind that is being examined, the dismissal of experience becomes untenable, even paradoxical ... to deny the truth of our own experience in the scientific study of ourselves is not only unsatisfactory; it is to render the scientific study of ourselves without a subject matter" (pp. 1314). With mental states, how they seem is how they are (e.g., Gallagher \& Zahavi, 2008; Klein, in press; Robinson, 2010; Shoemaker, 1984; Strawson, 2009).

\section{The Quantification and Objectification of Mental Reality}

Human experience does not easily submit to objectification and quantification (e.g., Mitchell, 1999; Robinson, 2008; Uttal, 2008). This often is taken as a tacit admission that experience forfeits its status as part of reality. As Stroud (2000) sees it, the goal of scientific naturalism is to separate "reality as it is independently of us from what is in one way or another dependent on us and so misleads us to what is really there" (p. 4; see also Sellers, 1963). On this view, objectivity trumps subjectivity in sanctioning what is real.

The doctrine that "reality" is that which distinguishes what "truly is the case" from that which "only appears to be" (a view having obvious Platonic origins) is seen by many as both overly restrictive and without firm foundation (e.g., Eccles, 1994; Elvee, 1992; Margenau, 1984; Papa-Grimaldi, 1998; Popper, 1994; Schommers, 1994; Swinburne, 2013; Trusted, 1999; Wallace, 2003). Dewey (1958) captures the tension between those who would restrict reality to what can be objectified and those who see no rational basis for banishing subjectivity from the realm of the real: "Since thinkers claim to be concerned with knowledge of existence, rather than imagination, they have to make good the pretention to knowledge. Hence . . . they remove the actual existence of the very traits which generate philosophic reflection and which give point and bearing to its conclusions." Reality, he continues, " . . . becomes what we wish it to be, after we have analyzed its defects and decided upon what would remove them; 'reality' is what existence would be if our reasonably justified preferences were so completely established in nature as to exhaust and define its entire being ... what is left over (and since trouble, struggle, conflict and error still empirically exist, something is left over), being excluded by definition from full reality is assigned a lower grade or order of being . . . a classificatory device has been introduced by which the two traits have been torn apart, one of them being labeled reality and the other appearance" (pp. 53-54; for similar views, see Bohm, 1980; Meixner, 2008; Nagel, 2012; Popper, 1994; Wallace, 2003).

This is not to say objectification and quantification of mental phenomenon is impossible. It is not! For more than 150 years, research in psychology has attested to the fact that the content of intrasubjective experience can be subjected to empirical analysis, providing descriptions and conclusions that attain intersubjective consensus. The phenomenological content of a mental state need not be arbitrary, ambiguous, or inexpressible. First-person experiences are reportable and thus subject to some degree of objectification and quantification. But, attempting maintain the depth and richness of experience by reducing them to mathematical formalism almost guarantees that something(s) essential are will be lost in the process (e.g., The Science of Psychology and Saving the Phenomena).

\section{Quantification}

An all too common refrain is that science is not science unless it involves the quantitative treatment of material reality (e.g., The Science of Psychology). And it is true that many great advances have been made by expressing reality in terms of mathematically formulated physical laws (e.g., Hanson, 1958; Klee, 1997; Ladyman, 2002; Margenau, 1950; Trusted, 1999).

However, many — perhaps most — of the fundamental issues of facing psychology are qualitative, not quantitative (e.g., Fodor, 1974; Gallagher \& Zahavi, 2008; Klein, 2014; Kohler, 1938; Midgley, 2014; Robinson, 2010). Quantitative analyses can be useful when they are related to experience, but they must not be allowed to stand in place of the experience itself: In determination of the nature of mental states, experience comes first.

Measurements and equations are supposed to sharpen thinking. But, particularly when positioned as the evidential basis for understanding 
the workings of mind, they have a tendency to become the object of scientific inquiry instead of auxiliary tests of crucial inferences. Quantification thus comes at the expense of the phenomenon. For example, the reduction of memory to a set of numbers (something we often do-e.g., number of words recalled; duration of retention; confidence judgment ratings, etc.) reduces the fullness of the memory experience to the point where it is a shadow (and that is being generous) of the phenomenon under investigation (e.g., Arcaya, 1989; Casey, 1979; Gallagher \& Zahavi, 2008).

Consider, for example, Sperling's (1960) classic study of sensory memory. Based exclusively on a reduction of participants' memory experience to numeric entries, he would have been forced to conclude that sensory memory for 9 visually presented letters was limited to approximately half the letters presented. However, Sperling decided to consider participants' subjective experience. Their introspective offerings alerted him to the possibility that his quantitative data failed to fully capture the properties of participants' memory experience. When queried, participants consistently maintained that they could remember more than 4.5 letters, but that their memories faded too quickly to be fully reported.

Taking heed of participants' experience, Sperling devised a new technique (the partial report) which revealed that, at least for a brief time, participants' remembered all 9 presented letters. In this way, he was able to capture a feature of sensory memory that would have eluded detection had he restricted his investigative scope (and the inferences it sanctioned) to evidence based on the reduction of experience to number.

\section{Objectification}

It is undeniable that many, if not all, of the notable achievements in modern science were made possible by the exclusion of "mind" from the world around us (e.g., Earle, 1955; Martin, 2008; Nagel, 2012). And, it is not hyperbole to maintain that the vast majority of scientists still show a considerable reluctance to engage in the study of experience - their own and that of others (e.g., Hurlburt \& Schwitzgebel, 2007; Wallace, 2003). However, as Nagel (2012) warns, at some point " . . . it will be necessary to make a new start on a more comprehensive understanding (of real- ity) that includes the mind" (p. 8; parenthesis added). Echoing these sentiments, Ricard and Thuan (2001) observe that "If we define the terrain field of science as what can be physically studied, measured, and calculated, then right from the start we leave out everything that is experienced in the first person ... If we forget this limitation, then we soon start affirming that the universe is everything that can be objectified in the third person, and only what is material" (p. 241).

As noted previously, objectification attempts to bestow scientific respectability on experiential phenomena by reducing them to a level at which they can be submitted to quantitative analysis. But, as argued in Saving the Phenomena, by so doing, the phenomena are impoverished to such a degree that they no longer bare clear resemblance to the way in which they were given to experience.

Consider, for example, the experience of pain. An attempt to scientifically legitimize this experience via objectification (e.g., the firing of C-fibers, limbic activity) typically is conjoined with quantification (e.g., the use of psychometric instruments such as Likert scales) to numerically capture the (a) type of pain (e.g., sharpness, dullness), (b) duration of pain event, (c) pain intensity, (d) overall level of discomfort, (e) frequency, and so forth.

Yet any objective collection of ratings and assessments, no matter how extensive, necessarily will fail to capture the richness of the experience (e.g., agony over the snail's pace of subjective time, the desperate longing for relief, the accompanying feelings of despair, stoicism, etc.). Just as the reduction of memorial experience to a tractable set of numeric values precludes appreciation of many of the very things that constitute memory phenomenon (e.g., meaning; feeling attachment to the past; reliving the experience; the emotionality attending that reliving) — so the attempt to reduce the experience of pain to an objective format has the effect of rendering the phenomenology unrecognizable. ${ }^{5}$

\footnotetext{
${ }^{5}$ Objectification is even more problematic when subjectivity itself (as opposed to the objects of subjectivity-i.e., the content of intentional states) is the target of inquiry. As discussed in Klein (2012), when objectivity is the stance adopted by subjectivity to study itself, that subjectivity must be directed toward what is not itself, but rather to some "other" that serves as its object. This has the effect of removing the target of inquiry (subjectivity) from investigation. Thus, objectification of the subjectivity (and its subsequent quantification) is not a logically coherent operation.
} 
Alleviating a pain event certainly is a laudable and humane objective. Considered from the standpoint of therapeutic efficacy, approaches that reduce pain experience to objective formalization can, and have been, very successful. This success, however, does not imply that a true understanding of the phenomena attains. And such understanding is, or at least should be, a goal of psychological inquiry. To fully appreciate the experience of pain (and pain $i$ s an experience), interventions based on objectification will only take one so far. A concerted effort to elevate pain phenomenology to theoretical "center stage" holds promise for a richer understanding of the behavioral outcomes attained. More, it provides direction for development of new and potentially more effective treatments based from a clear vision of what "pain" as a mental state consists in.

Lest there be doubt about the complexities of pain as an experience-complexities not easily captured via objectification-one need refer only to such seriously puzzling phenomena as pain asymbolia (i.e., feeling a pain as a pain, but not treating that feeling as a signal for fleeing the offending stimulus; e.g., Berthier, Starkstein, \& Leiguarda, 1988; Rubins \& Friedman, 1948; Schilder \& Stengel, 1931), the feeling of pain affect absent the feeling of pain sensation (e.g., Ploner, Freund, \& Schnitzler, 1999), pain that is not experienced as unpleasant (e.g., Bain, in press; Kahane, 2009), and related dissociations between pain experience and personal indifference (reviewed in Klein, 2014). Such mysteries (e.g., "are all pains unpleasant?"; "are all pains personally owned?") are essential to understanding pain phenomenology-mysteries not easily accommodated, much less appreciated, absent a clear focus on the mental state of "pain" in its experiential fullness.

\section{The Primacy of the Private}

One of the great technical achievements of modern psychology has been the development of radiological measures (e.g., fMRI, CAT, PET scans) and related technologies to map the presumed neural correlates of mental states. For example, an individual placed in an fMRI scanner may be asked to attend to some stimulus items (e.g., pictures of frightening events). On the basis of neural activity (e.g., assessed by increased blood flow to cortical regions) recorded during exposure to the stimuli, inferences are drawn about the anatomical underpinnings of the mental state of "fear."

Suppose our participant showed increased flow of oxygenated blood to regions $\mathrm{X}, \mathrm{Y}$, and $\mathrm{Z}$ (e.g., the amygdala and other limbic structures). What conclusions are sanctioned by such findings? The answer is that it depends critically on the individual's subjective reports. ${ }^{6}$ If our participant affirms that he is experiencing fear, inferences are warranted about the possible role of activated structures in his phenomenological realization of fear. However-and this is the critical point-if, despite the presence of consensually sanctioned fear-inducing stimuli and the activation of structures assumed (on the basis of theory and/or previous experimentation) to be implicated in the mental state "fear," if our participant does not experience that state, the objective data must take a back seat to his subjective experience.

In short, contrary to the materialist belief that the direct deliverances of our own experience are of little value unless they have received official scientific verification, in practice it is the experience, not the presumed mechanisms of its subjective instantiation, that guarantee its worth. As Robinson (2008) notes: "Where facts render a theory untenable, we must not jettison the facts!" (p. 81).

A take-away message is that even if some form of materialism is true (e.g., neutral monism-which includes conscious experience as an aspect of material reality without stripping it of its experiential properties; e.g., Russell, 1921/1949), it still is legitimate and important to treat experience and its content independently of any mathematical formalization or nonexperiential reduction. As we repeatedly have seen, mental events are not (at least at present) usefully translated into the language of the physical sciences. Accordingly, it is essential that we consider experience as it is given-at least to the extent that this currently is possible. To do

\footnotetext{
${ }^{6} \mathrm{I}$ am leaving aside a host of interpretive difficulties related to the inferences permissible from correlative findings involving variables that (depending on one's metaphysical assumptions) are presumed to embody different ontological commitments (i.e., objective and subjective), as well as questions pertaining to purely methodological considerations (for discussion, see Dumit, 2004 and Uttal, 2001).
} 
otherwise has the adverse (and unintended) effect of expunging from consideration the phenomena of interest.

\section{So, What Can We Do?}

While the nature of first-person subjectivity may be a source of methodological inconvenience, this does not justify its exclusion from scientific consideration or empower one to stipulate metaphysical emendations designed to compensate for empirical limitations. If our available techniques are unable to capture the properties of experience as experience, then so much the worse for our techniques.

Some strategies for a conceptual reorientation of our metaphysical commitments (i.e., treating experience as an irreducible aspect of reality) already are available, though underutilized. A promising approach-one sustainable within the context of current methodological sophistication-relies on a person's ability to recount the content of his or her introspections. Admittedly, introspective techniques suffer from a number of interpretive and methodological difficulties - for example, the effects of verbalization on the experience verbalized, the completeness of verbal reports, the validity of inferences based on analysis of response protocols (for review and discussion, see Ericsson \& Simon, 1985; Hurlburt \& Schwitzgebel, 2007). However, many (though not all) of these issues are surmountable (e.g., Brewer, 1994; Hurlburt, 1993). Accordingly, the use of introspective reports as a primary source of data has enjoyed a resurgence among psychologists during the past several decades (e.g., in domains such as autobiographical memory, self, consciousness, and temporal self-projection; e.g., Baars, 1988; Conway, Rubin, Spinnler, \& Wagenaar, 1992; Fivush \& Haden, 2003; Hurlburt, 1993; Klein, 2012; Nelson, 1989; Race, Keane, \& Verfaellie, 2011). As Hurlburt and Schwitzgebel (2007) observe, "Even hard-nosed neuroscientists ask their subjects about their subjectively felt experience while in the fMRI magnet" (p. 5). This is attributable, in large part, to the unique perspective introspective data provide - that is, an empirically justifiable vantage point from which to observe experiential reality in the fullness in which it is given (see The Quantification and Objectification of Mental Reality).
This approach to experiential reality-a merging of empiricism and phenomenologyattempts to save the phenomena by not saddling the investigator with a false choice between either (a) reducing a phenomenon to numerical values or, having failed to do so; (b) forfeiting a claim to scientific respectability. Rather, it focuses analysis on phenomena at a level that (hopefully) approaches that at which they are given in experience.

\section{The Science of Experiential Reality: What Needs Change Is the Metaphysics, Not the Approach}

It is important to be clear that I am not rejecting science. Rather, I am calling for a more inclusive realization of that approach to understanding what is real-one that addresses those aspects of the whole not currently accorded a position of explanatory relevance (largely the result of a materialist metaphysics that has been conjoined-in my view, unjustifiably_with modern science). Science is a wonderful way to gain knowledge of reality. But, in its current practice, aspects of reality are denied entry. Accordingly, we mistake the object of inquiry (having been stripped of its qualitative properties and reduced to a quantity), as wholly real, when in fact "the object, so treated, is an artificial abstraction ... something of its reality has been lost" (Lewis, 1947, p. 82).

In short, rather than an attack on science, I am suggesting a revision of our current practice of explaining away the whole by reducing it to numerical abstractions. One way to move closer to this goal is to accord experiential reality a secure place in our ontology (e.g., via greater application of methods-such as introspection-that seem better suited to capturing experience as experience). But it is possible that existing scientific methods, even stripped of their current metaphysical conceits, will need to be supplemented with and guided by (yet to be realized) methods better suited to addressing a revised conception of "all that is."

\section{A Look Toward the Future}

In my view, science needs to adopt a new, more inclusive, metaphysics (e.g., Earle, 1955; Gendlin, 1962; Kitchener, 1988; Klein, 2014; 
Martin, 2008; Meixner, 2008; Papa-Grimaldi, 1998), one in which reality is not reduced to only that which can be captured by current scientific methods. Reality is too broad to be fully apprehended by a single approach. Nor do we currently have any way of surveying the whole of reality. To maintain that all reality submits to current scientific method is to maintain without evidential or conceptual warrant that reality consists in its entirety of aspects capable of being fully grasped by a particular set of techniques and theoretical assumptions.

As recognition of the conceptual liabilities of attempting to force, in Procrustean fashion, all of reality into a "materialist bed" gains wider acceptance, new methods, better-suited to capturing its experiential aspects will need to be fashioned. As Gendlin (1962) observes, it would be prudent for psychology to “ . . . add a body of theory consisting of concepts of a different type-concepts that can refer to experiencing, and that can grasp the way in which experience functions [to] . . . distinguish this different order of concepts from logical and objective concepts, and to provide systematic methods for moving back and forth between the two orders" (p. 7). Driving at the heart of the matter, Rogers asks "Is there some view ... which might preserve the values of ... scientific advances . . . and yet find more room for the existing subjective person who is at the heart and base even of our system of science?" (cited in Gendlin, 1962, p. 48).

The point is that the scientific methods that currently dominate psychology do not (and perhaps cannot) directly tap the heart of our discipline-subjectivity. It is unreasonable to try to fill in our ignorance of the scope of reality with theories that describe only those pieces of the whole that can apprehended by our sense organs (with or without external aid) - that is, the objective, material world. As philosopher C. B. Martin (2008) concluded, after devoting himself to a study of these issues for more than half a century, if we wish to understand reality-its properties and the causal interactions manifested therein - "New and basic ways of thinking are needed" (p. 197).

To posit that mental experience is capable of being grasped by such finite aspects of reality as matter, energy, or, more abstractly, universal laws or Platonic forms, is a restrictive enter- prise - one that presupposes we have warrant to declare that reality, in its fullness, can be subsumed by such constructs (e.g., Gendlin, 1962; Jackson, 1986; Margenau, 1984; PapaGrimaldi, 1998; Varela et al., 1993; van Fraasen, 2005). It is the contention of this paper that we have no such warrant-and, in fact, we have evidence from our attempts to objectify and quantify first-person phenomenology that the consequences of adopting such a metaphysical stance renders a view of reality barren of a fundamental constituent. New methods, conceived of (revised) metaphysical necessity, should be at the top of the list the things psychology needs to do to if it is to maintain its status as an independent science (an aspiration that gave birth to the enterprise some 170 years ago); short of this, psychology is in danger of being seen as little more than a variant of biology or social anthropology.

\section{Final Thoughts}

With regard to human phenomenology, Varela et al. (1993) face the strain between science and the study of mind directly: "When it is cognition or mind that is being examined, the dismissal of experience becomes untenable, even paradoxical. The tension comes to the surface especially in cognitive science because cognitive science stands at the crossroads where the natural sciences and the human sciences meet" (p. 13). They continue "Neither extreme (material science or human science) is workable ... To deny the truth of our own experience in the scientific study of ourselves is not only unsatisfactory; it is to render the scientific study of ourselves without a subject matter. But, to suppose that science cannot contribute to an understanding of our experience may be to abandon, within the modern context, the task of selfunderstanding" (pp. 13-14, parenthesis added for clarification).

What we ultimately need is a unity of knowledge that considers all aspects of reality (subjective and objective) as real-on their own terms. And we must do so using all the tools currently available. If (as likely will be the case) it is found that these tools are not up to the task, then new ones need to be developed-with particular emphasis on the most complex tool of all-the human mind.

Our goal, in short, should be to establish a common ground between the neuro/computa- 
tional and experiential aspects of the mind-one that does not attempt to reduce one set of ontological commitments to the terms of the other. ${ }^{7}$ Only in this way can our appreciation for, and understanding of, our ability to experience ourselves as thinking, feeling, wanting, doing, beings-experiences which likely are what gave rise to psychology in the first place (Humphrey, 1984)- be constructively engaged.

\section{Coda: A Return to the Experience of Memory}

While attempting to recall the name of his childhood home (Kakania), Ulrich, the protagonist of Robert Musil's (1995) novel The Man Without Qualities experiences a "memory that hovered before (my mind's eye) . . . of white, wide, prosperous-looking roads dating from the era of foot marches and mail coaches, roads crisscrossing the country in every direction like rivers of order, like ribbons of bright military twill, the paper-white arm of the administration holding all the provinces in its embrace. And what provinces they were! Glaciers and sea, Karst limestone and Bohemian fields of grain, nights on the Adriatic chirping with restless cicadas and Slovakian villages where the smoke rose from the chimney as from upturned nostrils while the village cowered between two small hills as if the earth had parted its lips to the child between them ..." (p. 28).

The stark contrast between the depth, complexity and richness of Ulrich's memory experience and its representation as an "item recalled" (e.g., the word "Kakania") places in bold relief the gap between treatments of mental states rooted in the fertile ground of experiential reality and those issuing from the fallow (with respect to psychological reality) soil of materialist reduction.

\footnotetext{
${ }^{7}$ When I talk about a "unity of knowledge," I am proposing a conceptual unity by which we can better understand the connection between the "subjective/mental" and the "objective/material" aspects of reality. But what if there is no such conceptual unity to be had? Descartes (1984) believed there was no necessary connection between these two realms. What if he was right-i.e., that the connection between these aspects of reality is through and through contingent? Their contingent relationship was, according to Descartes, established by God and God might have established a different contingent relationship between them. Thus, to hold out hope for a unitive understanding,
}

must one simultaneously hold that Descartes was wrong: That he didn't see a contingent relationship between the two realms, but only failed to discern a necessary relationship? While I cannot convincingly demonstrate that unification is either a logical or nomological possibility, evidence presented in Klein (2014) suggests that a unitive understanding may be afforded by the largely overlooked (in contemporary psychological research) but critically important mental construct of "personal ownership of one's mental states" (see also, Klein, 2012 and Klein \& Nichols, 2012; Lane, 2012). The interested reader is referred to these sources (primarily Klein, 2014, chap. 5) for explication.

\section{References}

Arcaya, J. M. (1989). Memory and temporality: A phenomenological alternative. Philosophical Psychology, 2, 101-110. http://dx.doi.org/10.1080/ 09515088908572965

Baars, B. J. (1988). A cognitive theory of consciousness. New York, NY: Cambridge University Press.

Bain, D. (in press). Pains that don't hurt. Australasian Journal of Philosophy. http://dx.doi.org/ 10.1080/00048402.2013.822399

Berthier, M., Starkstein, S., \& Leiguarda, R. (1988). Asymbolia for pain: A sensory-limbic disconnection syndrome. Annals of Neurology, 24, 41-49. http://dx.doi.org/10.1002/ana.410240109

Bohm, D. (1980). Wholeness and the implicate order. London, United Kingdom: Routledge \& Kegan Paul.

BonJour, L. (2010). Against materialism. In R. C. Koons \& G. Baker (Eds.), The waning of materialism (pp. 3-24). New York, NY: Oxford University Press. http://dx.doi.org/10.1093/acprof:oso/ 9780199556182.003.0001

Brentano, F. (1995). Descriptive psychology. London, United Kingdom: Routledge.

Brewer, W. F. (1994). Autobiographical memory and survey research. In N. Schwarz \& S. Sudman (Eds.), Autobiographical memory and the validity of retrospective reports (pp. 11-20). New York, NY: Springer-Verlag. http://dx.doi.org/10.1007/ 978-1-4612-2624-6_2

Casey, E. S. (1979). Perceiving and remembering. The Review of Metaphysics, 32, 407-436.

Chalmers, D. J. (1996). The conscious mind: In search of a fundamental theory. New York, NY: Oxford University Press.

Churchland, P. S. (1986). Neurophilosophy: Toward a unified science of the mind-brain. Cambridge, MA: MIT Press.

Conway, M. A., Rubin, D. C., Spinnler, H., \& Wagenaar, W. A. (1992). Theoretical perspectives on autobiographical memory. London, United Kingdom: Kluwer Academic Publishers. http://dx.doi .org/10.1007/978-94-015-7967-4 
Danziger, K. (2008). Marking the mind: A history of memory. New York, NY: Cambridge University Press. http://dx.doi.org/10.1017/CBO9780511810626

Descartes, R. (1984). The philosophical writings of Descartes, 2 volumes. New York, NY: Cambridge University Press.

Dewey, J. (1958). Experience and nature. New York, NY: Dover Publications, Inc.

Dumit, J. (2004). Picturing personhood: Brain scans and biomedical identity. Princeton, NJ: Princeton University Press.

Earle, W. (1955). Objectivity: An essay on phenomenological ontology. New York, NY: The Noonday Press.

Ebbinghaus, H. (1885/1913). Memory: A contribution to experimental psychology $(\mathrm{H}$. A. Ruger \& C. Bussenius, Trans.). New York, NY: Teacher's College, Columbia University.

Eccles, J. C. (1994). How the self controls its brain. New York, NY: Springer-Verlag. http://dx.doi.org/ 10.1007/978-3-642-49224-2

Eddington, A. (1958). The philosophy of physical science. Ann Arbor, MI: The University of Michigan Press.

Elvee, R. Q. (1992). The end of science? Attack and defense: Nobel conference XXV. Lanham, MD: University Press of America, Inc.

Ericsson, K. A., \& Simon, H. A. (1985). Protocol analysis: Verbal reports as data. Cambridge, MA: The MIT Press.

Fivush, R., \& Haden, C. A. (2003). Autobiographical memory and the construction of a narrative self. Mahwah, NJ: Erlbaum.

Fodor, J. A. (1974). Special sciences (Or: The disunity of science as a working hypothesis). Synthese, 28, 97-115. http://dx.doi.org/10.1007/ BF00485230

Gallagher, I. (2000). Philosophical conceptions of the self: Implications for cognitive science. Trends in Cognitive Sciences, 4, 14-21. http://dx.doi.org/ 10.1016/S1364-6613(99)01417-5

Gallagher, S., \& Zahavi, D. (2008). The phenomenological mind. New York, NY: Routledge.

Gendlin, E. (1962). Experiencing and the creation of meaning: A philosophical and psychological approach to the subjective. Evanston, IL: Northwestern University Press.

Hanson, N. R. (1958). Patterns of discovery: An inquiry into the conceptual foundations of science. New York, NY: Cambridge University Press.

Humphrey, N. (1984). Consciousness regained: Chapters in the development of mind. New York: Oxford University Press.

Hurlburt, R. T. (1993). Sampling inner experience in disturbed affect. New York, NY: Plenum Press. http://dx.doi.org/10.1007/978-1-4899-1222-0
Hurlburt, R. T., \& Schwitzgebel, E. (2007). Describing inner experience? Proponent meets skeptic. Cambridge, MA: The MIT Press.

Jackson, F. (1986). What Mary didn't know. The Journal of Philosophy, 83, 291-295. http://dx.doi .org/10.2307/2026143

James, W. (1975). Pragmatism: A new name for some old ways of thinking. Cambridge, MA: Harvard University Press. (Original work published 1907)

Kahane, G. (2009). Pain, dislike and experience. Utilitas, 21, 327-336. http://dx.doi.org/10.1017/ S0953820809990070

Kitchener, R. F. (1988). The world of contemporary physics: Does it need a new metaphysics? Albany, NY: SUNY Press.

Klee, R. (1997). Introduction to the philosophy of science: Cutting nature at its seams. New York, NY: Oxford University Press.

Klein, S. B. (2012). The self and its brain. Social Cognition, 30, 474-518. http://dx.doi.org/10.1521/ soco.2012.30.4.474

Klein, S. B. (2014). The two selves: Metaphysical commitments and functional independence. New York, NY: Oxford University Press.

Klein, S. B. (in press). What memory is. Wiley Interdisciplinary Reviews: Cognitive Science.

Klein, S. B., \& Nichols, S. (2012). Memory and the sense of personal identity. Mind, 121, 677-702. http://dx.doi.org/10.1093/mind/fzs080

Koestler, A. (1959). The sleepwalkers: A history of man's changing vision of the universe. New York, NY: Arkana.

Koestler, A., \& Smythies, J. R. (1967). Beyond reductionism: The Alpbach Symposium. Boston, MA: Beacon Press.

Kohler, W. (1938). The place of value in a world of facts. New York, NY: Liveright Publishing Corporation.

Ladyman, J. (2002). Understanding philosophy of science. New York, NY: Routledge.

Lane, T. (2012). Toward an explanatory framework for mental ownership. Phenomenology and the Cognitive Sciences, 11, 251-286. http://dx.doi.org/ 10.1007/s11097-012-9252-4

Lewis, C. S. (1947). The abolition of man. New York, NY: Macmillan Publishing Company.

Margenau, H. (1984). The miracle of existence. Woodbridge, CT: Ox Bow Press.

Margenau, H. (1950). The nature of physical reality. New York, NY: McGraw-Hill.

Martin, C. B. (2008). The mind in nature. New York, NY: Oxford University Press.

Medawar, P. B. (1968/1980). Induction and intuition in scientific thought. Philadelphia, PA: American Philosophical Society.

Meixner, U. (2005). Physicalism, dualism and intellectual honesty. Dualism Review, 1, 1-20. 
Meixner, U. (2008). The reduction of reductive and non-reductive materialism-And a new start. In A. Antonietti, A. Corradini, \& E. J. Lowe (Eds.), Psycho-physical dualism: An interdisciplinary approach (pp. 143-166). Boulder, CO: Rowman \& Littlefield Publishers, Inc.

Midgley, M. (2014). Are you an illusion? New York, NY: Routledge.

Mitchell, J. (1999). Measurement in psychology: A critical history of a methodological concept. New York, NY: Cambridge University Press. http://dx .doi.org/10.1017/CBO9780511490040

Musil, R. (1995). The man without qualities. New York, NY: Alfred A Knopf Inc.

Nagel, T. (1974). What is it like to be a bat? The Philosophical Review, 83, 435-450. http://dx.doi .org/10.2307/2183914

Nagel, T. (2012). Mind \& Cosmos: Why the materialist neo-Darwinian conception of nature is almost certainly wrong. New York, NY: Oxford University Press. http://dx.doi.org/10.1093/acprof:oso/ 9780199919758.001.0001

Nelson, K. (1989). Narratives from the crib. Cambridge, MA: Harvard University Press.

Nisbett, R. E., \& Wilson, T. D. (1977). Telling more than we can know: Verbal reports on mental processes. Psychological Review, 84, 231-259. http:// dx.doi.org/10.1037/0033-295X.84.3.231

Papa-Grimaldi, A. (1998). Time and reality. Aldershot, United Kingdom: Ashgate.

Ploner, M., Freund, H.-J., \& Schnitzler, A. (1999). Pain affect without pain sensation in a patient with a postcentral lesion. Pain, 81, 211-214. http://dx .doi.org/10.1016/S0304-3959(99)00012-3

Popper, K. R. (1994). Knowledge and the body-mind problem: In defense of interaction. London, United Kingdom: Routledge.

Race, E., Keane, M. M., \& Verfaellie, M. (2011). Medial temporal lobe damage causes deficits in episodic memory and episodic future thinking not attributable to deficits in narrative construction. The Journal of Neuroscience, 31, 10262-10269. http://dx.doi.org/10.1523/JNEUROSCI.1145-11 .2011

Reichenbach, H. (1951). The rise of scientific philosophy. Berkeley, CA: University of California Press.

Rescher, N. (1984). The limits of science. Berkeley, CA: University of California Press.

Ricard, M., \& Thuan, T. X. (2001). The quantum and the lotus. New York, NY: Three Rivers Press.

Robinson, D. N. (2008). Consciousness and mental life. New York, NY: Columbia University Press.

Robinson, D. N. (2010). Consciousness: The first frontier. Theory \& Psychology, 20, 781-793. http://dx.doi.org/10.1177/0959354310369944

Rosch, E. (1997). Mindfulness meditation and the private (?) self. In U. Neisser \& D. A. Jopling (Eds.), The conceptual self in context (pp. 185202). New York, NY: Cambridge University Press.

Rubins, J. L., \& Friedman, E. D. (1948). Asymbolia for pain. Archives of Neurology and Psychiatry, 60, 554-573. http://dx.doi.org/10.1001/archneurpsyc .1948.02310060007002

Russell, B. (1921/1949). The analysis of mind. London, United Kingdom: George Allen \& Unwin Ltd.

Schilder, P., \& Stengel, E. (1931). Asymbolia for pain. Archives of Neurology and Psychiatry, 25, 598-600. http://dx.doi.org/10.1001/archneurpsyc .1931 .02230030156007

Schommers, W. (1994). Space and time, matter and mind: The relationship between reality and spacetime. London, United Kingdom: World Scientific. http://dx.doi.org/10.1142/2439

Sellers, W. (1963). Science, Perception and Reality. London, United Kingdom: Routledge \& Kegan Paul.

Shoemaker, S. (1984). Identity, cause and mind. New York, NY: Oxford University Press.

Sperling, G. (1960). The information available in brief visual presentations. Psychological Monographs, 74, 1-29.

Stevens, S. S. (1946). On the theory of scales of measurement. Science, 103, 677-680. http://dx.doi .org/10.1126/science.103.2684.677

Strawson, G. (2009). Mental reality (2nd ed.). Cambridge, MA: MIT Press. http://dx.doi.org/10.7551/ mitpress/9780262513104.001.0001

Stroud, B. (2000). The quest for reality: Subjectivism \& the metaphysics of color. New York, NY: Oxford University Press.

Swinburne, R. (2013). Mind, brain, and free will. New York, NY: Oxford University Press.

Tallis, R. (2008). The enduring significance of Parmenides: Unthinkable thought. London, United Kingdom: Continuum International Publishing Group.

Trusted, J. (1999). The mystery of matter. New York, NY: St. Martin's Press. http://dx.doi.org/10.1057/ 9780230597211

Tulving, E., \& Szpunar, K. K. (2012). Does the future exist? In B. Levine \& F. L. M. Craik (Eds.), Mind and the frontal lobes (pp. 248-263). New York, NY: Oxford University Press.

Uttal, W. R. (2001). The new phrenology. Cambridge, MA: MIT Press.

Uttal, W. R. (2008). Time, space, and number in physics and psychology. Cornwall-on-Hudson, NY: Sloan Publishing.

van Fraasen, B. C. (2005). Transcendence of the ego (The non-existent knight). In G. Strawson (Ed.), The self? (pp. 87-110). Malden, MA: Blackwell Publishing. 
Varela, F. J., Thompson, E., \& Rosch, E. (1993). The embodied mind: Cognitive science and human experience. Cambridge, MA: The MIT Press.

Vaihinger, H. (1925). The philosophy of "as if." New York, NY: Harcourt, Brace, \& Company, Inc.

Wallace, R. A. (2003). Choosing reality: A Buddhist view of physics and the mind. Ithaca, NY: Snow Lion Publications.

Williams, T. (2002). Vagueness, identity and Leibniz' law. In P. Giaretta, A. Bottani, \& M. Carrara (Eds.), Individuals, essence and identity: Themes of analytic metaphysics (pp. 273-303). Dordrecht, The Netherlands: Kluwer Academic Publishers. http://dx.doi.org/10.1007/978-94-017-1866-0_14

Wolpert, L. (1992). The unnatural nature of science. London, United Kingdom: Faber.

Received October 15, 2014

Revision received November 3, 2014

Accepted November 3, 2014 